\title{
Entry of Trypanosoma (Schizotrypanum) dionisii to Macrophages in vitro and its Subsequent Fate Therein
}

\author{
Bý A. J. LISTON* AND J. R. BAKER \\ Medical Research Council Biochemical Parasitology Unit, Molteno Institute, \\ Downing Street, Cambridge CB2 3EE
}

(Received 1 February 1978)

\begin{abstract}
Observations by phase contrast, fluorescence and electron microscopy showed that epimastigotes of Trypanosoma (Schizotrypanum) dionisii (grown in vitro) were phagocytosed posterior end first by mouse peritoneal macrophages in vitro. Many were subsequently digested as a result of phagosome-lysosome fusion but others survived by apparently inhibiting this fusion and/or escaping from the phagosome into the host cell's cytoplasm. These survivors replicated as amastigotes. Long trypomastigotes, separated from populations grown in vitro by passage down a column of glass beads (with or without prior exposure to guinea-pig serum), were phagocytosed by either pole and all were subsequently digested.
\end{abstract}

\section{INTRODUCTION}

Trypanosoma dionisii is phagocytosed by mouse peritoneal macrophages in vitro and some organisms survive to replicate intracellularly (Baker \& Liston, 1978). This paper describes the process of endocytosis and the parasites' subsequent fate. Some preliminary observations have been published (Liston, 1975; Baker et al., 1977).

\section{METHODS}

Trypanosomes. Trypanosoma (Schizotrypanum) dionisii Bettencourt \& França, 1905 was maintained in L4NHS medium at $28{ }^{\circ} \mathrm{C}$. Unless otherwise specified, clone no. 3 of stock $\mathbf{P} 3$ was used; in some experiments uncloned stock P3, or the similar stock P2, were employed. Details of isolation, maintenance and cloning are given by Baker et al. (1976).

Macrophages. Peritoneal macrophages were collected from unstimulated male Parke's surgically derived [P(SD)] mice (Baker \& Liston, 1978). For some electron microscopical observations, donor mice had been injected intradermally with $10^{7} T$. dionisii $\mathrm{P} 3$ emulsified in Freund's Incomplete Adjuvant $28 \mathrm{~d}$ previously.

Light microscopy. Portions $(1.5 \mathrm{ml})$ of a macrophage suspension $\left(3 \times 10^{5} \mathrm{ml}^{-1}\right.$ in medium 199; Baker \& Liston, 1978) were incubated at $37^{\circ} \mathrm{C}$ in Wild Selecta tissue culture observation chambers (Leitz, Luton, LU1 3HP) for $24 \mathrm{~h}$. The medium was then replaced by 199 containing $20 \%(\mathrm{v} / \mathrm{v})$ Wellcome heat-inactivated calf serum number 1 (WCS1) and $0.9 \times 10^{6}$ to $2 \cdot 1 \times 10^{6} \mathrm{ml}^{-1}$ epimastigotes or trypomastigotes of clone 3 or stock P2 prepared according to Baker et al. (1976) (sometimes omitting the initial treatment with guinea-pig serum). Cultures were kept at 35 or $37 \pm 0 \cdot 1^{\circ} \mathrm{C}$ by a thermistor-controlled fan heater (Klein \& Law, 1976), examined by phase contrast microscopy and photographed by electronic flash illumination on Ilford Pan $F$ film (ASA25).

Some cultures were supravitally stained with acridine orange 21667 (G. T. Gurr) in medium 199 (10 $\mu \mathrm{g}$ $\mathrm{ml}^{-1}$ ) for 25 to 60 (usually 30) min at $37^{\circ} \mathrm{C}$ (D'Arcy Hart \& Young, 1975), either 0 to 90 min before or 24 to $72 \mathrm{~h}$ after addition of trypanosomes. Cultures were then rinsed with medium 199 before incubation in medium 199 with serum $\left(37^{\circ} \mathrm{C}, 1\right.$ to $\left.4 \mathrm{~h}\right)$ to allow localization of stain within lysosomes. Cultures were

* Present address: London School of Hygiene and Tropical Medicine, Winches Farm Field Station, 395 Hatfield Road, St Albans, Hertfordshire AL4 0XQ. 
examined by phase contrast and dark-field fluorescence microscopy ( $\lambda$ max. $\sim 400 \mathrm{~nm}$, Leitz Heine condenser) and photographed on Kodak Ektachrome film (ASA160).

Electron microscopy. (i) Monolayer cultures. Plastic tissue culture flasks (Falcon $25 \mathrm{~cm}^{2}$; Becton, Dickinson \& Co., Wembley, HA9 OPS) contained $4 \times 10^{6}$ macrophages in $8 \mathrm{ml}$ medium 199 with $20 \%$ WCS1 or $16 \%$ WCS1 plus $4 \%$ heat-inactivated calf serum (Gibco Bio-Cult, Paisley, PA3 4EP) to ensure better cell adherence: $24 \mathrm{~h}$ later $2.4 \times 10^{7} \mathrm{~T}$. dionisii $\mathrm{P} 3$ (uncloned) were added. After $5 \mathrm{~d}$ at $32{ }^{\circ} \mathrm{C}$ or $3 \mathrm{~d}$ at $35^{\circ} \mathrm{C}$, cells were harvested by treatment $\left(5 \mathrm{~min}, 37^{\circ} \mathrm{C}\right.$ ) with $0.25 \%$ (w/v) trypsin (Difco, $1: 2500$ ) in phosphate-buffered saline (PBS; Dulbecco's solution A, Oxoid), washed twice in PBS $\left(4{ }^{\circ} \mathrm{C}, 400 \mathrm{~g}, 5 \mathrm{~min}\right.$ ) and fixed at $4{ }^{\circ} \mathrm{C}$ either for $1 \mathrm{~h}$ in osmium tetroxide/glutaraldehyde solution (Hirsch \& Fedorko, 1968) in 0.2 M-cacodylate buffer or for $2 \mathrm{~h}$ in $5 \%(\mathrm{v} / \mathrm{v})$ glutaraldehyde in $0.1 \mathrm{M}-$ Sorensen's phosphate buffer (SB, $\mathrm{pH} 7 \cdot 4)$. They were then washed $\left(4{ }^{\circ} \mathrm{C}, 400 \mathrm{~g}, 5 \mathrm{~min}\right)$ in $0.2 \mathrm{M}$-cacodylate buffer plus $5 \%(\mathrm{w} / \mathrm{v})$ sucrose or in SB and centrifuged $\left(50{ }^{\circ} \mathrm{C}, 600 \mathrm{~g}, 5 \mathrm{~min}\right.$ ) in molten $1 \%$ (w/v) Ionagar no. 1 (Oxoid). Cubes (about $1 \mathrm{~mm}^{3}$ ) were postixed for $2 \mathrm{~h}$ in $1 \%$ (w/v) osmium tetroxide in SB (if initially fixed with glutaraldehyde only), washed in SB, dehydrated in ethanol and embedded in Epon via propylene oxide. Sections were stained with $2 \%$ (w/v) aqueous uranyl acetate and aqueous lead citrate (Reynolds, 1963) for 2 min each.

(ii) Suspension cultures. Washed T. dionisii (as above) were added to macrophages ( 7 trypanosomes per macrophage) suspended in medium 199 plus $20 \%$ WCS1 in $2 \mathrm{ml}$ screw-capped plastic ampoules (no. 506; Sterilin, Teddington, TW11 8QZ). After 10 or 20 min at $37^{\circ} \mathrm{C}$ with occasional shaking, cultures were centrifuged $\left(20^{\circ} \mathrm{C}, 400 \mathrm{~g}, 5 \mathrm{~min}\right)$ and fixed in $2.5 \%$ glutaraldehyde in SB, centrifuged in agar, postfixed (1 or $2 \mathrm{~h}$ ), dehydrated and embedded as described above (but using Taab resin; Taab Laboratories, Reading, Berks).

(iii) Lysosomal labelling. (a) Monolayer cultures were treated, $24 \mathrm{~h}$ after initiation, with ferritin (Taab) in medium $199\left(0.5 \mathrm{mg} \mathrm{ml}^{-1} ; 4 \mathrm{~h}, 37^{\circ} \mathrm{C}\right.$; Jones \& Hirsch, 1972), washed and then incubated in medium 199 with $20 \%$ serum $\left(4 \mathrm{~h}, 37^{\circ} \mathrm{C}\right)$. Clone 3 (mainly epimastigotes) were added at 10 trypanosomes per macrophage. After $1 \mathrm{~h}$ at $37^{\circ} \mathrm{C}$, cultures were fixed in $2 \%(\mathrm{v} / \mathrm{v})$ glutaraldehyde in SB $\left(1 \mathrm{~h}, 4^{\circ} \mathrm{C}\right)$; cells were scraped off the substrate (Alexander \& Vickerman, 1975), centrifuged in agar, postfixed and embedded as described above. (b) Cultures of $2 \times 10^{8}$ macrophages in $2 \mathrm{ml}$ medium 199 in $28 \mathrm{ml}$ glass Universal bottles were incubated, about $18 \mathrm{~h}$ after initiation, in $0.2 \%(\mathrm{w} / \mathrm{v})$ saccharated iron oxide in medium $199\left(3 \mathrm{~h}, 37^{\circ} \mathrm{C}\right.$; Alexander \& Vickerman, 1975), washed and incubated in medium 199 plus $10 \%$ WCS1 for $1 \mathrm{~h}$. Then $1 \times 10^{7}$ epimastigotes of clone 3 were added. After $18 \mathrm{~h}$, cultures were fixed and prepared for electron microscopy as described by Alexander \& Vickerman (1975).

\section{RESULTS}

\section{Attachment and entry to macrophages}

Early experiments were at 32 or $35^{\circ} \mathrm{C}$, but most were at $37^{\circ} \mathrm{C}$. No difference was observed between events occurring at the different temperatures.

Immediately after their introduction, epimastigotes became attached to macrophages by their posterior tip. Entry followed during the next $10 \mathrm{~min}$, apparently by phagocytosis (Figs 1 and 2) (Baker \& Liston, 1978). Trypomastigotes, however, became attached by either their anterior or posterior ends, and entered (again apparently by phagocytosis) either end first (depending which end had become attached to the cell). After entry, both forms became coiled up in parasitophorous vacuoles and remained motile, the trypomastigotes in particular moving like coiled springs (Fig. 3). Many endocytosed epimastigotes and all trypomastigotes were digested within 24 to $48 \mathrm{~h}$, but some epimastigotes survived, became rounded and

Figs 1 to 3. Serial phase contrast photomicrographs of an epimastigote (p) of $T$. dionisii $\mathrm{P} 3$ being phagocytosed by a mouse peritoneal macrophage at $35^{\circ} \mathrm{C}$ in vitro: Fig. $1,0 \mathrm{~min}$; Fig. $2,7 \mathrm{~min}$; Fig. 3, 10 min. Bar markers represent $10 \mu \mathrm{m}$.

Fig. 4. Phase contrast photomicrograph of a macrophage after exposure in vitro to $T$. dionisii $\mathbf{P} 3$ at $37^{\circ} \mathrm{C}$ for $5 \mathrm{~d}$. Some intracellular amastigotes (a) appear to be in vacuoles and others ( $\mathrm{a}^{\prime}$ ) free in the cytoplasm; some have become vacuolated (av). Bar marker represents $10 \mu \mathrm{m}$.

Figs 5 and 6. Paired phase contrast $(a)$ and fluorescence $(b)$ photomicrographs of macrophages exposed to $T$. dionisii $\mathrm{P} 3$ epimastigotes at $37^{\circ} \mathrm{C}$ and labelled in vitro with acridine orange either $90 \mathrm{~min}$ before (Fig. 5) or $48 \mathrm{~h}$ after (Fig. 6) exposure to parasites. Some live parasites (p) are adjacent to host-cell secondary lysosomes (hsl). A large phagolysosome (Fig. 5, hpl) contains a vacuolated non-motile parasite $\left(p^{\prime}\right)$. In Fig. 6, one cell containing many intact amastigotes (a) entirely lacks fluorescent label. Bar markers represent $10 \mu \mathrm{m}$. 


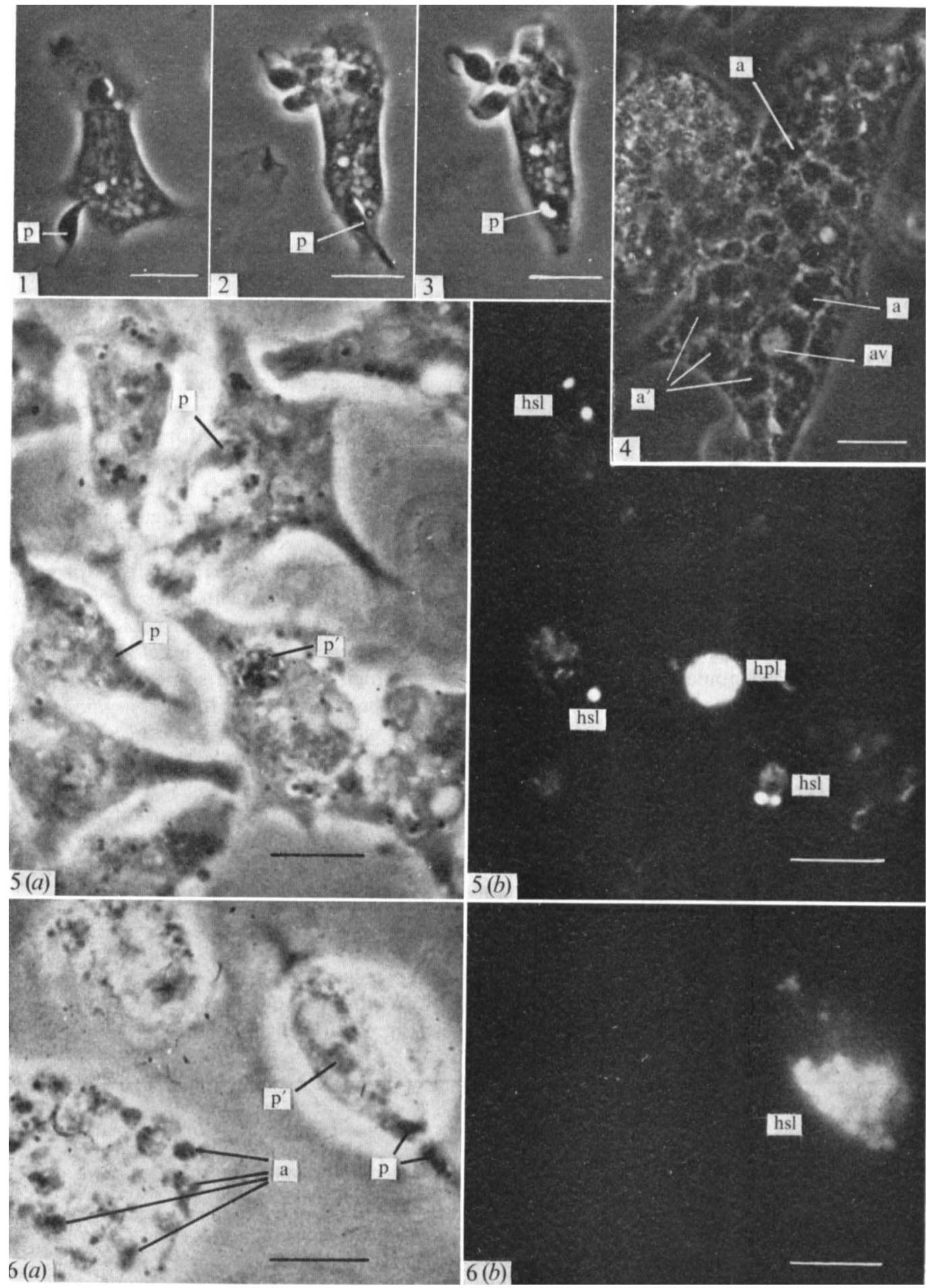


subsequently replicated by binary fission (Fig. 4). Epimastigotes also multiplied extracellularly in the supernatant medium, and continued to enter macrophages throughout the observation period $(96 \mathrm{~h})$. Consequently, rolled-up epimastigotes and amastigotes were seen throughout this period; later, some of them were not surrounded by obvious vacuoles (compare electron microscopic observations reported below).

\section{Fluorescence microscopy}

Acridine orange in lysosomes of macrophages and parasites fluoresced bright orange-red under blue-violet light. More lysosomes were seen in macrophages that were well spread after several days in culture. Some macrophages which appeared rounded under phase contrast illumination were packed with lysosomes, presumably indicating autolysis. Lysosomes were also seen at the posterior tip of parasites, epimastigotes having up to four or five and trypomastigotes only one large one. Trypanosome kinetoplasts and nuclei of parasites and macrophages fluoresced green.

Addition of trypanosomes immediately after applying acridine orange to cultures was unsatisfactory, resulting in a green halo around living attached and intracellular parasites. When the dye was allowed to localize in the lysosomes of macrophages for $90 \mathrm{~min}$ before $3 \mathrm{~h}$ exposure to trypanosomes, living intracellular parasites, whether in large phagosomes or not, were not associated with dye. Large lysosomes could be seen next to living parasites but fusion with the parasitophorous vacuoles had not occurred. Trypanosomes obviously undergoing digestion were surrounded by large fluorescing phagolysosomes (Fig. 5). If cultures were infected $48 \mathrm{~h}$ before exposure to acridine orange, cells in which much digestion was evident were heavily labelled. Again living parasites not in large parasitophorous vacuoles had no associated dye. One cell harbouring several apparently viable amastigotes contained no detectable fluorochrome (Fig. 6). Macrophages in cultures infected $72 \mathrm{~h}$ before addition of dye contained numerous fluorescing lysosomes, which surrounded some of the living dividing intracellular parasites but had not fused with the latters' parasitophorous vacuoles. Some viable parasites were completely unassociated with lysosomes; yet others, and all digested parasites, were contained in large fluorescing vacuoles, indicating phagosomelysosome fusion.

Macrophages in cultures with pure populations of trypomastigotes invariably showed fusion of lysosomes with parasitophorous vacuoles, often even while the parasite was being ingested. This correlated with the observed occurrence in Giemsa-stained control preparations of their complete digestion within 24 to $48 \mathrm{~h}$.

\section{Electron microscopy}

In monolayer cultures, after phagocytosis by macrophages (Fig. 7), rolled-up epimastigotes or amastigotes were often seen surrounded by a closely applied membrane (Fig. 8) or apparently free in the cytoplasm of macrophages (Fig. 9). In cells incubated at $32{ }^{\circ} \mathrm{C}$, they

Figs 7 to 13. Electron micrographs of thin sections of mouse peritoneal macrophages cultured in vitro with $T$. dionisii $\mathrm{P} 3$ (Figs 10,11 ) or clone 3 (Figs 7, 8, 9, 12, 13). All except Fig. 11 were from: monolayer cultures; Figs 7, 8, 9, macrophages labelled with saccharated iron oxide and exposed for $18 \mathrm{~h}$ to epimastigotes at $37^{\circ} \mathrm{C}$; Fig. 10, macrophage from an immunized mouse after exposure to T. dionisii at $32^{\circ} \mathrm{C}$ for $5 \mathrm{~d}$; Fig. 11, macrophage from a suspension culture 20 min after addition of $T$. dionisii at $37^{\circ} \mathrm{C}$; Figs 12, 13, macrophages labelled with ferritin and exposed for $1 \mathrm{~h}$ to $T$. dionisii at $37^{\circ} \mathrm{C}$. Bar markers represent $1 \mu \mathrm{m}$.

Fig. 7. Dividing epimastigote (p) apparently undergoing phagocytosis posterior end foremost.

Fig. 8. Parasite (p) in closely applied vacuole (hpv) with no label, alongside a similar vacuole containing label but no parasite, presumably a phagolysosome (hpl).

Fig. 9. Intact parasite (p) apparently free in cytoplasm alongside a vacuole containing a digested parasite $\left(\mathrm{p}^{\prime}\right)$ with associated label, indicating phagosome-lysosome fusion. 

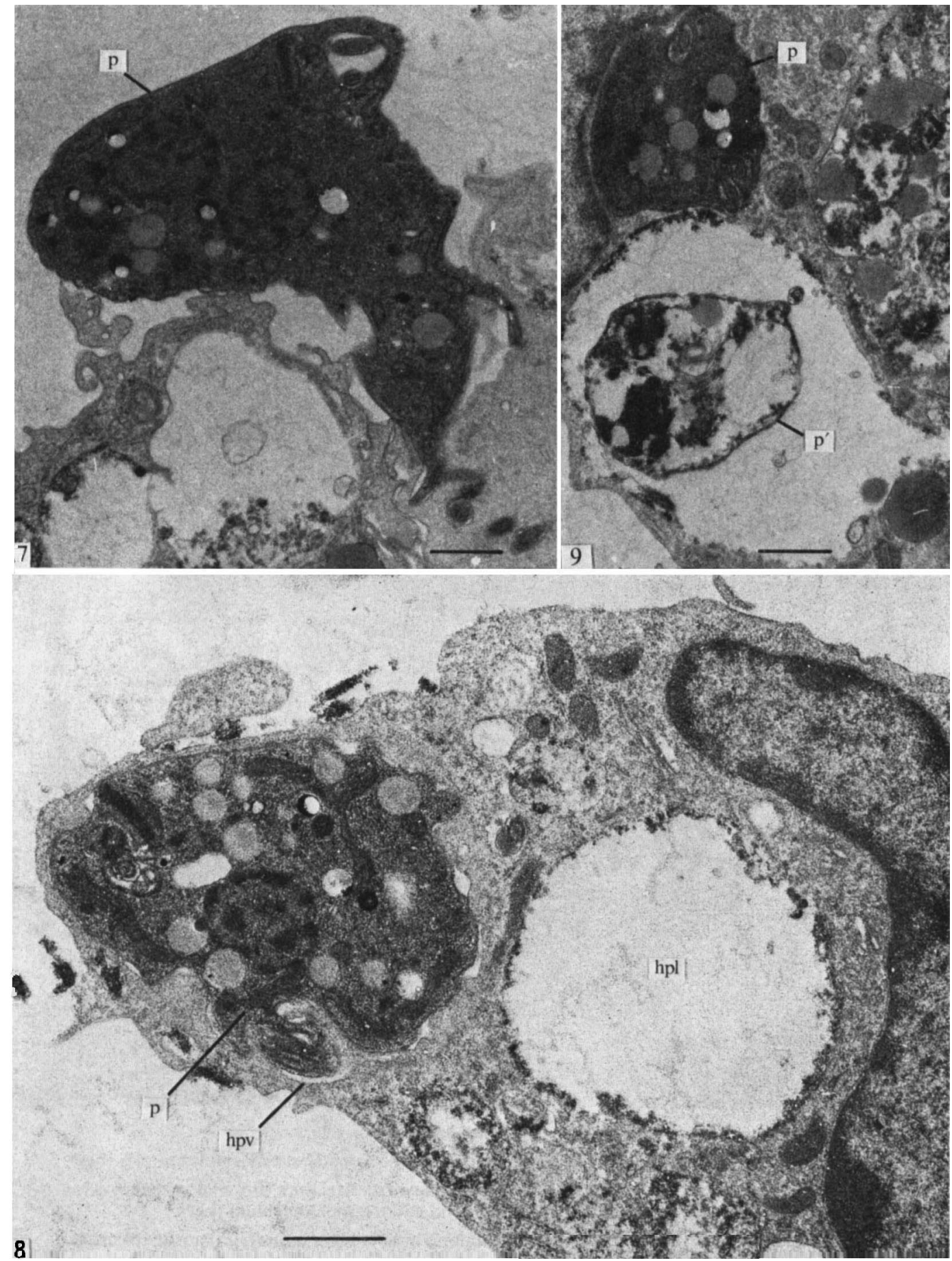


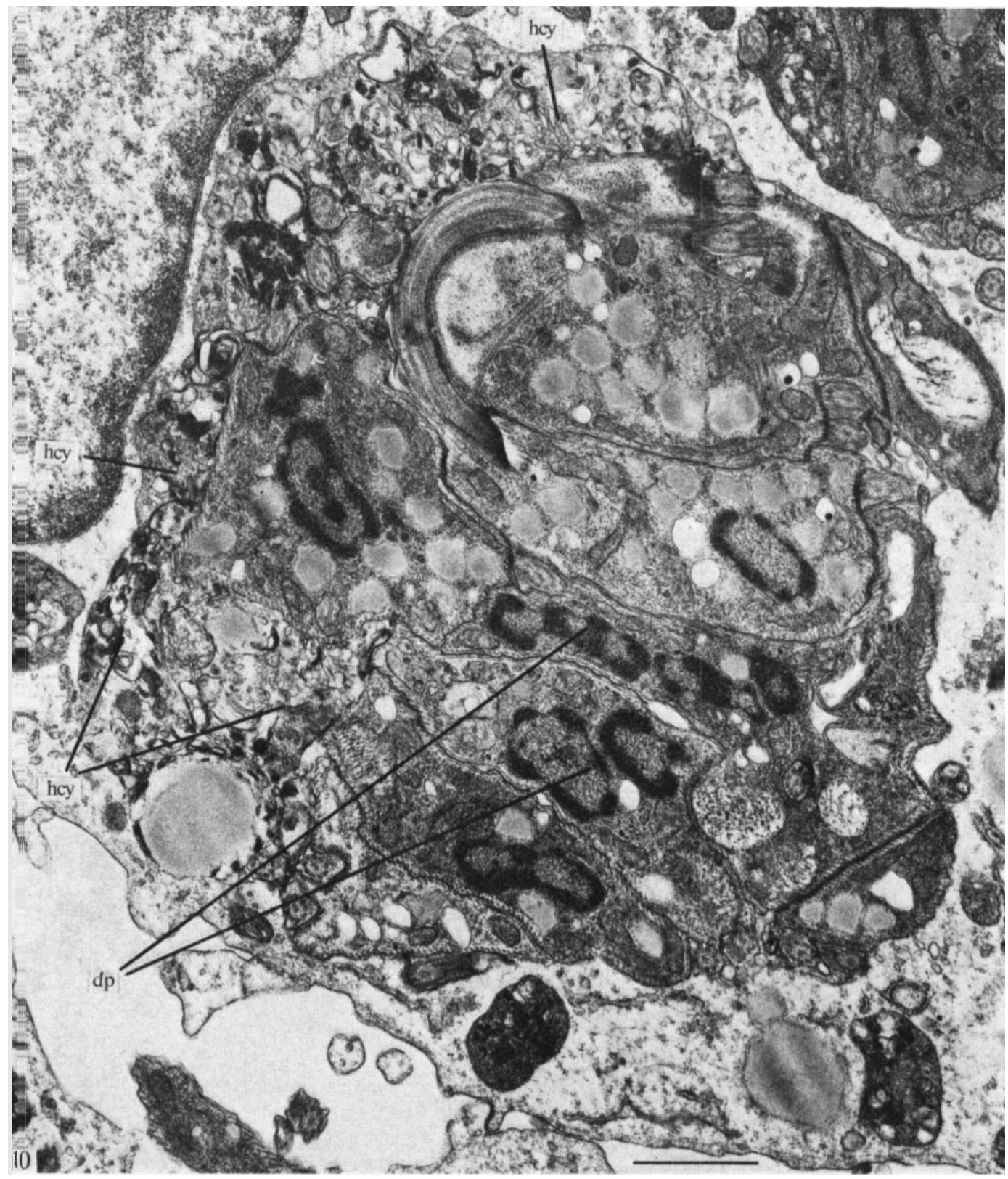

For general details, see legend on p. 256.

Fig. 10. Intracellular parasites, some dividing (dp), with associated host-cell cytolysosomes (hcy).

Fig. 11. Rolled-up parasite [with nucleus (pn), kinetoplast (k), flagellum (fm) and mitochondrion (pm)] surrounded by host-cell mitochondria (hem) and endoplasmic reticulum (her).

Fig. 12. Labelled secondary lysosomes (hsl) and endoplasmic reticulum (her); a parasite (p) undergoing phagocytosis has no associated label.

Fig. 13. Secondary lysosomes (hsl) and larger vacuoles, presumably phagolysosomes (hpl) containing parasite material $(\mathrm{fm})$ and associated label. An intact parasite $(\mathrm{p})$ is in a parasitophorous vacuole without label. 


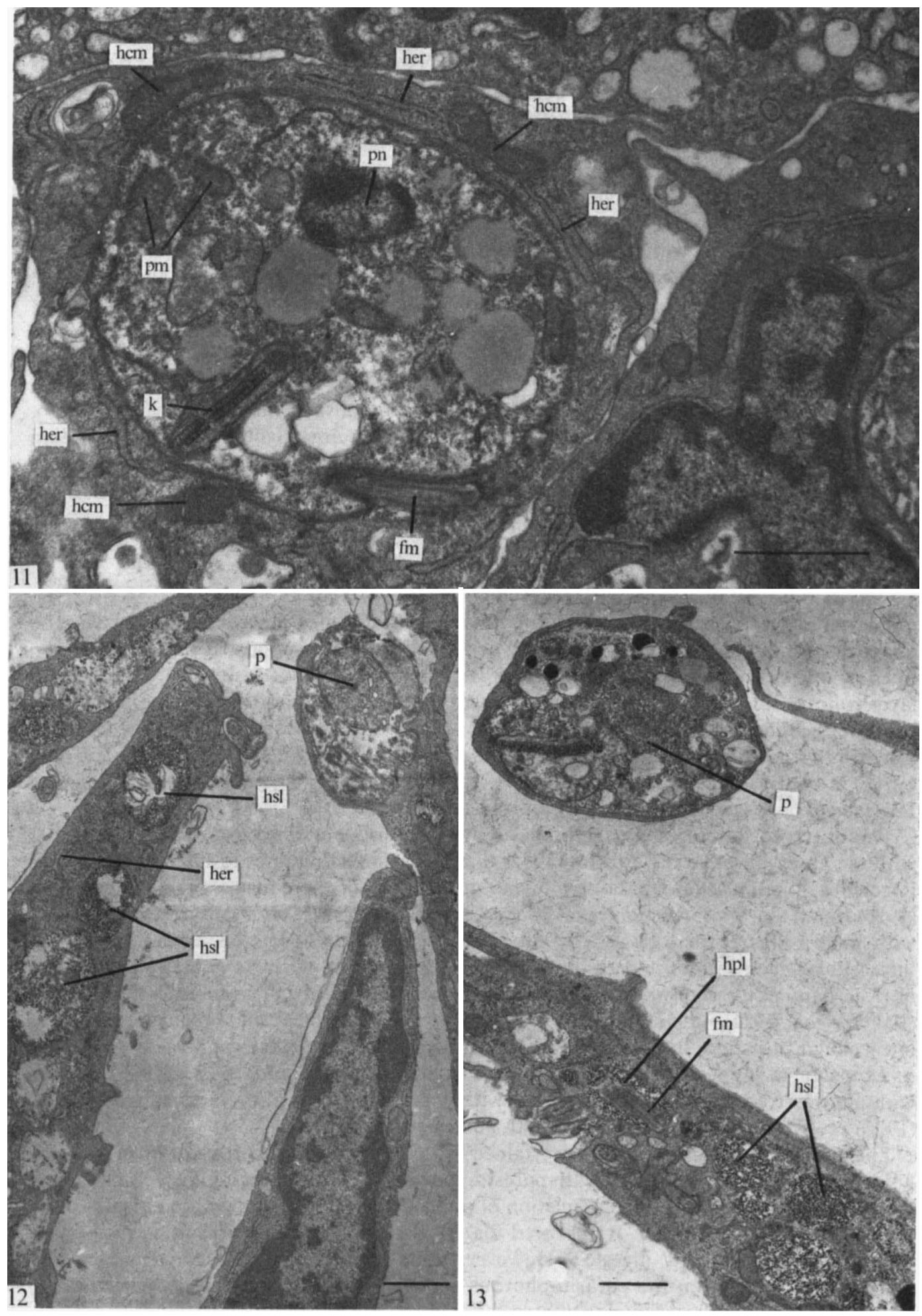


were frequently next to membrane-bound vesicles containing partially digested host-cell organelles, presumably cytolysosomes or autophagosomes (Fig. 10), the intervening membrane often being thick and osmiophilic; such appearances were less common in cells incubated at $35^{\circ} \mathrm{C}$, though no other consequence of the temperature difference was noticed. Dividing parasites, probably amastigotes, were seen (Fig. 10). No obvious difference was noted between infected macrophages from normal or immune mice. In suspension cultures only, some epimastigotes were attached to macrophages by their flagella and some parasitophorous vacuoles were surrounded by host-cell mitochondria and endoplasmic reticulum (Fig. 11).

Macrophages treated with ferritin before being exposed to trypanosomes for $1 \mathrm{~h}$ contained the label in their endoplasmic reticulum, primary and secondary lysosomes, and presumed autophagosomes (Fig. 12). Parasites undergoing phagocytosis had no associated ferritin (Fig. 12), nor did those intracellular forms surrounded by a closely applied membrane, but larger vacuoles, presumably phagolysosomes, contained parasites and ferritin (Fig. 13).

Macrophages treated with saccharated iron oxide and subsequently exposed to trypanosomes for $18 \mathrm{~h}$ possessed large labelled vacuoles (some also containing parasite debris), presumably phagolysosomes (Fig. 9). An apparently viable amastigote with no surrounding host membrane had no associated label, while an adjacent vacuole contained a digested parasite and label, indicating phagosome-lysosome fusion (Fig. 9); another intact parasite surrounded by a closely applied membrane was unlabelled, while a nearby large vacuole contained the oxide (Fig. 8).

\section{DISCUSSION}

The inference from direct observations that parasites enter macrophages passively by phagocytosis, after attachment to the host-cell membrane, is supported by the inhibition of entry into cells treated with cytochalasin B or trypsin (Baker \& Liston, 1978). In monolayer cultures this attachment was almost invariably by the posterior pole of epimastigotes and by either end of trypomastigotes. Most previous workers also reported entry of trypanosomatids posterior end first (see, for example, Akiyama \& Haight, 1971 ; Nogueira \& Cohn, 1976); in contrast, Miller \& Twohy (1967) reported that phagocytosis by macrophages of Leishmania donovani promastigotes occurred flagellar end first.

The observed failure of any trypomastigotes to survive within macrophages contrasts with the observation by Baker et al. (1972) that higher infection rates resulted in HeLa cells infected with populations containing higher proportions of these forms. Nogueira \& Cohn (1976) found that trypomastigotes of $T$. cruzi, separated from in vitro cultures by treatment with guinea-pig serum followed by albumen gradient centrifugation, could initiate an intracellular cycle in mouse peritoneal macrophages in vitro, whereas epimastigotes could not. Perhaps passage down a column of glass beads, part of our preparatory procedure (Baker et al., 1976), impaired in some way the trypomastigotes' subsequent resistance to intracellular digestion, though they remained fully motile. The effect cannot have been due to exposure to guinea-pig serum, since inocula of trypomastigotes of stock P2 prepared without this treatment failed to survive within macrophages; also, Nogueira \& Cohn's (1976) preparations had been treated with guinea-pig serum.

The observations on preparations stained with acridine orange suggest that host-cell lysosomes may fuse very rapidly with parasitophorous vacuoles containing trypomastigotes or epimastigotes - even before completion of phagocytosis of the former and at least within $1 \mathrm{~h}$ of ingestion of the latter. It appeared that all parasites within the resulting phagolysosomes were subsequently digested. However, some intracellular epimastigotes survived, either by escaping from the parasitophorous vacuoles into the host-cell cytoplasm or by apparently inhibiting lysosomal fusion with the vacuoles (which remained small and barely detectable by light microscopy) as reported by Khavkin \& Freidlin (1977). The presence of acridine orange in vacuoles containing apparently viable parasites in macrophages labelled 
$72 \mathrm{~h}$ previously could have been due to recent endocytosis of surviving replicating extracellular parasites and need not imply resistance to digestion for the full $72 \mathrm{~h}$. Electron microscopy supported this view, by showing that all morphologically intact and replicating parasites were either surrounded by a closely apposed host-cell membrane, enclosing no lysosomal marker, or were apparently free in the macrophage's cytoplasm. Resistance of T. cruzi to digestion has been ascribed to its escape from the phagosome (see, for example, Nogueira \& Cohn, 1976; Kress et al., 1975, 1977; Milder et al., 1976, 1977), in contrast to Leishmania spp., which seem able to survive even in the presence of lysosomal contents within phagolysosomes (Alexander \& Vickerman, 1975; Chang \& Dwyer, 1976, 1978; Lewis \& Peters, 1977), and Toxoplasma gondii which was described as being 'walled off' from host-cell lysosomes by the macrophage's mitochondria and endoplasmic reticulum (Jones \& Hirsch, 1972). The significance of this 'walling off', also seen in some of our material, is not clear; it appeared to be an exceptional occurrence probably resulting from mechanical displacement of the host-cell organelles by the phagocytic vacuole.

We thank Miss J. Price, Miss L. Maxwell, Mrs A. Wisby and Dr D. C. Barker for skilled assistance in obtaining electron micrographs, and Dr Barker also for advice on their interpretation; Miss L. F. Selden gave much general help and encouragement. This work was partially supported by a grant from the Ministry of Overseas Development.

\section{REFERENCES}

Akiyama, H. J. \& Haight, R. D. (1971). Interaction of Leishmania donovani and hamster peritoneal macrophages. A phase contrast microscopical study. American Journal of Tropical Medicine and Hygiene 20, 539-545.

Alexander, J. \& Vickerman, K. (1975). Fusion of host cell secondary lysosomes with the parasitophorous vacuoles of Leishmania mexicanainfected macrophages. Journal of Protozoology 22, 502-508.

BAKER, J. R. \& Liston, A. J. (1978). Trypanosoma (Schizotrypanum) dionisii: effect of various agents on attachment and entry to macrophages in vitro and on morphogenesis. Journal of General Microbiology 104, 79-89.

Baker, J. R., Green, S. M., Chaloner, L. A. \& GaBoraK, M. (1972). Trypanosoma (Schizotrypanum) dionisii of Pipistrellus pipistrellus (Chiroptera): intra- and extracellular development in vitro. Parasitology 65, 251-263.

BAKer, J. R., Liston, A. J. \& SElden, L. F. (1976). Trypomastigote dimorphism and satellite deoxyribonucleic acid in a clone of Trypanosoma (Schizotrypanum) dionisii. Journal of General Microbiology 97, 113-115.

Baker, J. R., Liston, A. J. \& Selden, L. F. (1977). Early interaction between host-cell and parasite in Schizotrypanum species. Abstracts of Papers Read at the Fifth International Congress on Protozoology, p. 461. Edited by S. H. Hutner. New York.

Chang, K.-P. \& DWyer, D. M. (1976). Multiplication of a human parasite (Leishmania donovani) in phagolysosomes of human macrophages in vitro. Science 193, 678-680.

Chang, K.-P. \& DWyer, D. M. (1978). Leishmania donovani hamster macrophage interactions in vitro: cell entry, intracellular survival, and multi- plication of amastigotes. Journal of Experimental Medicine 147, 515-530.

D'Arcy Hart, P. \& Young, M. R. (1975). Interference with normal phagosome-lysosome fusion in macrophages, using ingested yeast cells and suramin. Nature, London 256, 47-49.

Hirsch, J. G. \& Fedorko, M. E. (1968). Ultrastructure of human leukocytes after simultaneous fixation with glutaraldehyde and osmium tetroxide and postfixation in uranyl acetate. Journal of Cell Biology 38, 615-628.

JoNES, T. C. \& HiRsCH, J. G. (1972). The interaction between Toxoplasma gondii and mammalian cells. II. The absence of lysosomal fusion with phagocytic vacuoles containing living parasites. Journal of Experimental Medicine 136, 1173-1194.

Khavkin, Th. N. \& Freidlin, I. S. (1977). A fluorescence phase contrast study of the interaction between Toxoplasma gondii and lysosomes in living cells. Zeitschrift für Parasitenkunde 52, 19-21.

KLEIN, R. A. \& LAW, D. T. (1976). Heated microscope stage with precise temperature control. Laboratory Practice 25, 160-161.

Kress, Y., BloOM, B. R., WittNer, M., RoWen, A. \& TANOWITZ, H. (1975). Resistance of Trypanosoma cruzi to killing by macrophages. Nature, London 257, 394-396.

Kress, Y., Tanowitz, H., Bloom, B. R. \& WitTNeR, M. (1977). Trypanosoma cruzi: infection of normal and activated mouse macrophages. Experimental Parasitology 41, 385-396.

Lewis, D. H. \& Peters, W. (1977). The resistance of intracellular Leishmania parasites to digestion by lysosomal enzymes. Annals of Tropical Medicine and Parasitology 71, 295-312.

Liston, A. J. (1975). Trypanosoma (Schizotrypanum) dionisii in macrophage cultures. 1. Preliminary observations on entry into cells. Parasitology 71, xviii. 
Miller, H. C. \& Twohy, D. W. (1967). Infection of macrophages in culture by leptomonads of Leishmania donovani. Journal of Protozoology 14, 781-789.

Milder, R., Kloetzel, J. \& Deane, M. P. (1976). Interaction of peritoneal macrophages and Trypanosoma cruzi. Revista do Instituto de medicina tropical de São Paulo 18, 139.

Milder, R., Kloetzel, J. \& Deane, M. P. (1977). Observations on the interaction of peritoneal macrophages with Trypanosoma cruzi. II. Intra- cellular fate of bloodstream forms. Revista do Instituto de medicina tropical de São Paulo 19, 313322.

Nogueira, N. \& Cohn, Z. (1976). Trypanosoma cruzi: mechanism of entry and intracellular fate in mammalian cells. Journal of Experimental Medicine 143, 1402-1420.

ReYNOLDS, E. S. (1963). The use of lead citrate at high $\mathrm{pH}$ as an electron opaque stain in electron microscopy. Journal of Cell Biology 17, 206-212. 